\title{
Synthesis and Characterization of Electroactive Films Deposited from Aniline Dimers
}

\author{
M. A. Cotarelo, ${ }^{\mathrm{a}}$ F. Huerta, ${ }^{\mathrm{b}}$ C. Quijada, ${ }^{\mathrm{b}}$ R. Mallavia, ${ }^{\mathrm{c}}$ and J. L. Vázquez ${ }^{\mathrm{a}, \mathrm{z}}$ \\ ${ }^{a}$ Departamento Química Física, Universidad de Alicante, E-03080 Alicante, Spain \\ ${ }^{b}$ Departamento Ingeniería Textil y Papelera, Universidad Politécnica de Valencia, E-03801 Alcoy, Spain \\ ${ }^{c}$ Instituto de Biología Molecular y Celular, Universidad Miguel Hernández, E-03202 Elche, Spain
}

\begin{abstract}
The electrochemical oxidation of the aniline dimers 2-aminodiphenylamine (2-adpa) and 4-aminodiphenylamine (4-adpa) has been performed in strongly acidic medium on platinum, graphite, and indium tin oxide electrodes. The resulting films have been characterized by a number of electrochemical, microscopic, and spectroscopic techniques in order to gain some insight on their respective chemical structures. Both poly(2-adpa) and poly(4-adpa) are electroactive species which differ significantly one from another. It was found that aged poly(4-adpa) displayed electrochemical, morphologic and spectroscopic characteristics similar to those shown by polyaniline. On the contrary, poly(2-adpa) is really a mixture of three oligomerization products. The two main oligomers contain both open-ring and cycled phenazine centers, although their chemical structures seem to differ in the cap-end of the chain growth. The third oligomer is a minor product which seems a highly symmetric macrocycle involving several 2 -adpa molecules.
\end{abstract}

(C) 2006 The Electrochemical Society. [DOI: 10.1149/1.2198010] All rights reserved.

Manuscript submitted February 6, 2006; revised manuscript received March 10, 2006. Available electronically May 12, 2006.

The field of conducting polymers has become a subject of growing interest for electrochemists over the last 20 years. Formerly, these materials were synthesized through the action of strong chemical oxidants, namely persulfates, over an appropriate monomer such as aniline. ${ }^{1}$ However, the use of electrochemical methods spread gradually and now they are used as widely as the chemical methods. It is expected that most of the industrial applications of these polymers could take advantage of their electron-conducting properties, which can be tuned by applying an external current. Particularly polyaniline (Pani) is one of the most promising materials from a technological standpoint because of its high environmental stability. However, the low solubility in common organic solvents and the strong dependence of its electrical conductivity on the $\mathrm{pH}$ of the electrolytic medium (which falls almost to zero at $\mathrm{pH}$ higher than $3^{1,2}$ ) are inherent problems that should be overcome for future commercial purposes.

In this context, great effort has been made toward the synthesis of modified Pani structures, either from the polymerization of substituted monomers ${ }^{3-6}$ or from the introduction of functional groups after synthesis of the polymer. ${ }^{7,8}$ This effort resulted in the enhancement of a variety of properties such as mechanical, electrical, catalytic, or optical, among others. However, it is frequently found that improving a given property, such as solubility, results in the deterioration of others, such as electrical conductivity. ${ }^{9}$ In this way, a compromise between the involved properties should be reached. Another possible route to achieve these purposes could be the copolymerization between aniline and substituted aniline monomers such as the carboxylated, sulfonated, etc. ${ }^{9-11}$ In particular, there exist some reports focused on the "copolymerization" of aniline with either 4-aminodiphenylamine (4-adpa) $)^{12-15}$ or 2-aminodiphenylamine (2-adpa), ${ }^{16,17}$ which are merely aniline dimers with no additional functionalization (Scheme 1)

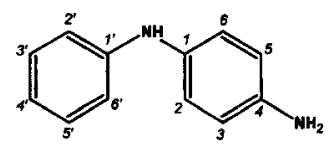

4-aminodiphenylamine (4-adpa)

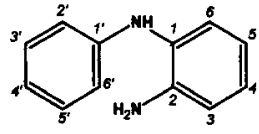

2-aminodiphenylamine (2-adpa)

Scheme 1.

Interestingly, these copolymers showed markedly different behavior from that of the original Pani. Thus, poly(aniline-co-4adpa) exhibits an enhanced electroactivity in aqueous buffering solutions of $\mathrm{pH}$ comprised between 3 and 8, even though it was not possible to synthesize large amounts of this material. ${ }^{18}$ In addition, catalytic properties of poly(aniline-co-4adpa) toward the oxidation of some organic and inorganic redox couples have also been reported in those media. ${ }^{19}$ Regarding poly(aniline-co-2adpa), it was reported that it can be copolymerized electrochemically in mineral acid medium. ${ }^{17}$ It was found that by keeping constant the aniline content, the copolymer growth rate falls as the 2-adpa concentration is increased. The obtained copolymer was characterized by optical spectroscopy and found to be structurally different from polyaniline and more soluble in organic solvents.

Polymers obtained from the electrochemical homopolymerization of either 4-adpa or 2-adpa monomers have received much less attention. ${ }^{17,20-22}$ Kitani et al. ${ }^{20}$ prepared a conducting polymer derived from 4-adpa in aqueous $\mathrm{HCl}$ solution whose conductivity and molecular mass were significantly smaller than those of Pani. It was reported that four monomeric units can couple to give an oligomeric product with a molecular mass around 2800 , but no deeper characterization of this material was performed. Later, Geniès et al. ${ }^{21}$ studied the polymerization mechanism in anhydrous hydrofluoric acid medium and, in agreement with Kitani's previous assumptions, found that the differences between poly(4-adpa) and Pani arise from the distinct polymerization mechanisms. More recently, Zimmerman et al. ${ }^{22}$ performed an interesting study on the initial stages of both aniline and 4-adpa electropolymerization by in situ Fourier transform infrared/attenuated total reflection (FTIR/ATR) and UV-visible spectroscopies. They confirmed the formation of tetrameric structures during the electrochemical oxidation of 4-adpa. With regard to the polymerization of 2-adpa, the lack of bibliographic information is still more apparent than for its para isomer. To our knowledge, only the paper by Chen et al. ${ }^{17}$ reported the homopolymerization of 2-adpa. Since that paper focused mainly on its copolymerization reaction with aniline, the results obtained for poly(2-adpa) were limited to the growth of the film by cyclic voltammetry (CV) and the analysis of the corresponding UV-visible spectrum. Hence, the present work aims to gain a deeper insight on the electrochemical homopolymerization of the aniline dimers 2-adpa and 4-adpa in strongly acidic medium. Special attention will be paid to the characterization of the polymeric films by a number of microscopic and spectroscopic techniques.

\section{Experimental}

The chemicals used in this work were all of reagent grade. 2-Aminodiphenylamine and 4-aminodiphenylamine were supplied 
by Aldrich and used as received. The electrolytic medium employed in the voltammetric experiments was $1 \mathrm{M} \mathrm{HCl}$ prepared with $18.2 \mathrm{M} \Omega \mathrm{cm}$ resistivity water. In situ FTIR experiments were conducted in $0.1 \mathrm{M} \mathrm{HCl}$ solutions in order to minimize the damage to the IR window. The working electrode employed for the synthesis of the polymer films was typically a spherical polycrystalline platinum surface of about $4 \mathrm{~mm}^{2}$. Polymers examined in the in situ FTIR or $\mathrm{X}$-ray photoelectron spectroscopy (XPS) spectrometers were grown on a mirror-polished Pt disk electrode, whereas those examined by a scanning electron microscope (SEM) were synthesized on a graphite rod electrode. The counter electrode was always a platinum wire. All potentials are referred to the reversible hydrogen electrode (RHE), which was immersed in the working solution through a Luggin capillary. As a previous step to electropolymerization, the platinum electrode was thermally cleaned in a propane-air flame. The electrode was then transferred to the polymerization medium which was previously deaerated by bubbling $\mathrm{N}_{2}$. Graphite electrodes were polished first with emery paper, then with diamond of decreasing grain sizes, and finally thoroughly washed with water and sonicated for $10 \mathrm{~min}$. Cyclic voltammograms were recorded at $50 \mathrm{mV} \mathrm{s}^{-1}$ and at room temperature.

A Nicolet Magna 850 spectrometer equipped with a liquid nitrogen-cooled HgCdTe detector was employed for the in situ FTIR experiments. The spectroelectrochemical cell was made of glass and provided with a prismatic $\mathrm{CaF}_{2}$ window beveled at $60^{\circ}$. All the spectra were collected at $8 \mathrm{~cm}^{-1}$ resolution and are presented in the form $\Delta R / R$. XPS spectra were recorded in a VG-Microtech Multilab 3000 electron spectrometer using a nonmonochromatized $\mathrm{Mg}-\mathrm{K} \alpha$ $(1253.6 \mathrm{eV})$ radiation source of $300 \mathrm{~W}$. The pressure of the analysis chamber during the scans was about $5 \times 10^{-7} \mathrm{~N} \mathrm{~m}^{-2}$. Photoelectron kinetic energies were measured in the fixed analyzer transmission mode at a pass energy of $50 \mathrm{eV}$.The intensities of the different contributions were obtained by integration of the corresponding peak area after the corresponding baseline correction. The experimental curves were adjusted to a combination of Lorentzian (30\%) and Gaussian $(70 \%)$ lines. Peak area ratios are computed after correction by tabulated atomic sensitivity factors. All binding energies (BEs) were referred to the line of the $\mathrm{C} 1 \mathrm{~s}(284.6 \mathrm{eV})$ and were recorded with an accuracy of $\pm 0.2 \mathrm{eV}$. The scanning electron microscopy (SEM) images were obtained with a Hitachi S-3000N instrument. In situ UV-visible spectra were collected with an AvaSpec spectrophotometer equipped with a linear 2048 pixel charge-coupled device (CCD) detector. The spectroelectrochemical experiments were performed in a $1 \mathrm{~cm}$ pathlength quartz cell employing an optically transparent indium-tin oxide (ITO) working electrode, a platinum wire as a counter electrode, and a reversible hydrogen (RHE) as the reference electrode. Before each experiment, the ITO-coated quartz electrode was degreased by immersion in acetone, rinsed with ultrapure water, and finally sonicated during several minutes. Fresh ITOcoated quartz plates were used for every experiment. Nuclear magnetic resonance spectra were collected on a Bruker AVANCE 500 spectrometer. The spectra were collected at $296 \mathrm{~K}$ in deuterated chloroform, and the resonance of the solvent was used as the reference for shift-tabulated values.

\section{Results and Discussion}

Electrochemical homopolymerization of 4-adpa and 2-adpa monomers. - CV curves recorded during the electrochemical oxidation of 4-adpa on a platinum electrode in aqueous hydrochloric acid solutions are displayed in Fig. 1a. The clean working electrode was immersed at a controlled potential of $0.06 \mathrm{~V}$ vs RHE in the polymerization medium and the voltammetric curves were recorded by cyclic scanning of the potential between the immersion potential and $0.8 \mathrm{~V}$ at a constant sweep rate of $50 \mathrm{mV} \mathrm{s}^{-1}$. The first forward scan shows that the onset of monomer oxidation occurs at $0.68 \mathrm{~V}$ and the peak current is centered at around $0.77 \mathrm{~V}$. Part of the species generated from the oxidation of 4-adpa can be reduced reversibly as evidenced by the small cathodic peak at $0.74 \mathrm{~V}$ on the first reverse
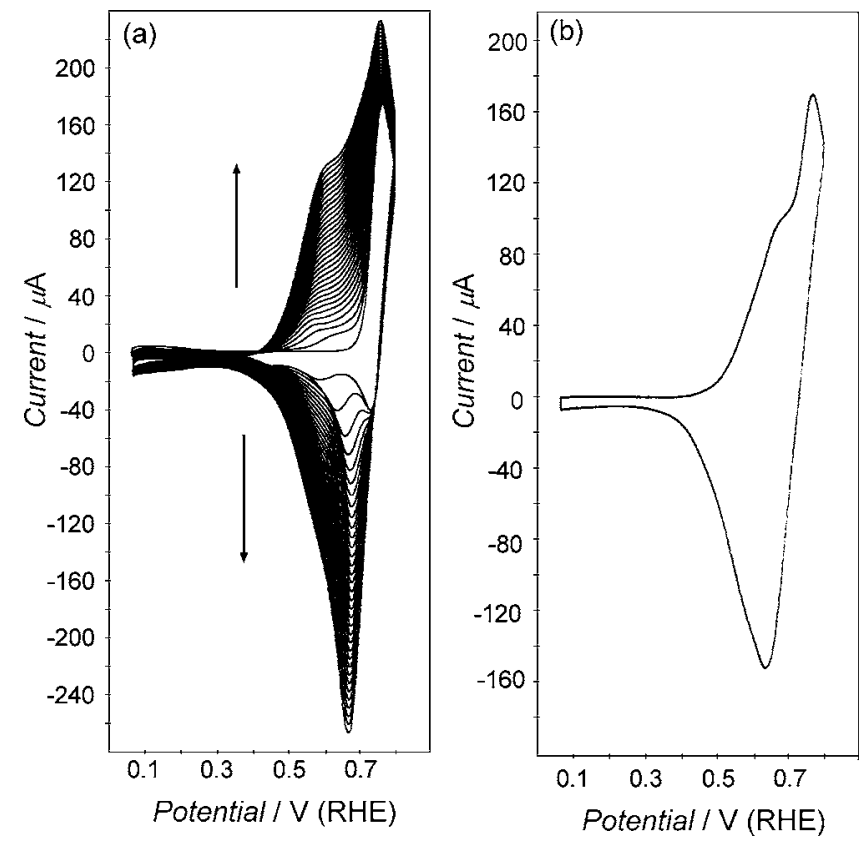

Figure 1. (a) $\mathrm{CVs}$ recorded in $1 \mathrm{M} \mathrm{HCl}$ during the electrochemical oxidation of $2.5 \mathrm{mM} 4$-adpa on a platinum electrode. (b) Voltammetric response of poly(4-adpa) in $1 \mathrm{M} \mathrm{HCl}$ solution free of monomer. Scan rate $50 \mathrm{mV} \mathrm{s}^{-1}$.

scan. The peak separation value approaches $30 \mathrm{mV}$, thus suggesting that the electrochemical oxidation involves two electrons per 4-adpa molecule. Accordingly, the reaction may be written as (Scheme 2)

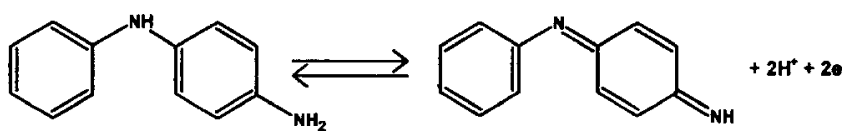

Scheme 2.

The low voltammetric charge recorded for the cathodic peak at $0.74 \mathrm{~V}$ seems in agreement with the possibility that most of those 4-adpa molecules oxidized at the positive end of the CV could react through chemical reactions, like dimerizations, in such a way that only a small amount of oxidized 4-adpa monomers could be available for reduction on the reverse sweep. ${ }^{23,24}$ Partially overlapped with the peak at $0.74 \mathrm{~V}$, an additional cathodic feature appears initially near $0.64 \mathrm{~V}$ and shifts slightly to positive potential values upon cycling. This feature is closely related with the anodic one centered at $0.61 \mathrm{~V}$, which develops in subsequent potential scans. The charge recorded for both the anodic and cathodic peaks increases steadily upon cycling, thus pointing to the slow growth of a polymeric material on the surface of the electrode, which will be henceforth referred to as poly(4-adpa). It is well known that the oxidation of polyaniline under similar experimental conditions gives rise to two distinct voltammetric peaks which can be related with the reversible redox transitions of the polymer to emeraldine and pernigraniline forms, respectively. Because 4-adpa is the main dimer generated during aniline oxidation, ${ }^{25}$ it was expected that the chemical structure of poly(4-adpa) was quite similar to that of polyaniline, i.e., resulting mainly from the coupling of monomers to the para position of the growing chain. ${ }^{20}$ However, only one redox process coming from a polymeric material was observed at around $0.6 \mathrm{~V}$. This potential is intermediate between those ascribed to the leucoemeraldine-emeraldine $(\sim 0.45 \mathrm{~V})$ and emeraldinepernigraniline $(\sim 1.0 \mathrm{~V})$ transitions. Redox peaks at intermediate 


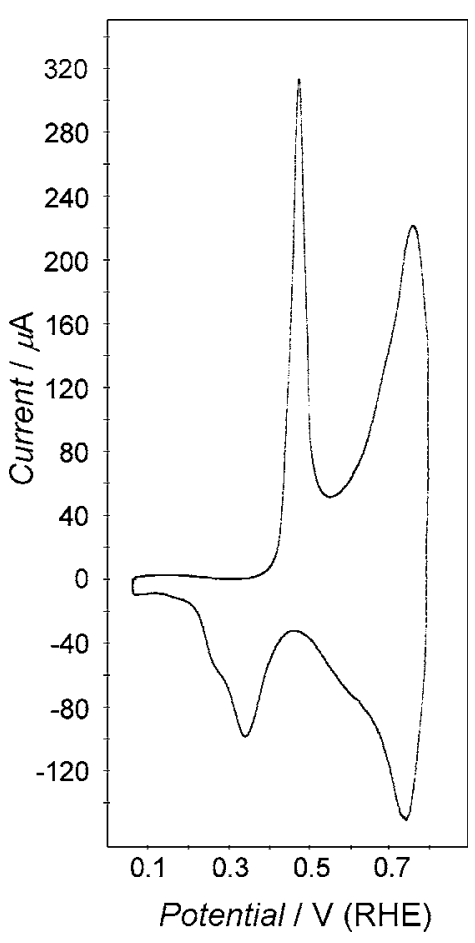

Figure 2. Voltammetric response of a poly(4-adpa) film dried for $24 \mathrm{~h}$ under vacuum. $1 \mathrm{M} \mathrm{HCl}$ background solution free of 4-adpa monomer. Scan rate $50 \mathrm{mV} \mathrm{s}^{-1}$.

potentials have usually been ascribed to the reversible redox processes undergone by soluble species such as benzoquinones. ${ }^{13,25}$ To check this possibility, poly(4-adpa) was generated under strong stirring of the working solution, but the redox transitions observed in Fig. 1a still remained in the CV. Therefore, it was assumed that the pair of peaks are related to species attached to the electrode surface. In order to examine the electrochemical behavior of poly(4-adpa) in the absence of monomeric species, a platinum electrode covered with the polymer generated after 30 polymerization cycles was extracted from the working medium and transferred to a clean $1 \mathrm{M}$ $\mathrm{HCl}$ solution with no rinsing step in order to prevent the film loosening. Upon withdrawal, the freshly prepared film was in the form of a hanging membrane attached to the platinum spherical electrode. It was observed that the film occluded a small amount of the polymerization solution and showed a greenish-blue color and a weak adherence to the substrate. The electrochemical behavior of the synthesized material in $1 \mathrm{M} \mathrm{HCl}$ solution free of monomer is depicted in Fig. 1b. A redox process centered at around $0.7 \mathrm{~V}$, in agreement with the process observed during the electropolymerization of the monomer in Fig. 1a. In addition to this pair of voltammetric peaks, Fig. $1 \mathrm{~b}$ shows an anodic feature at around $0.77 \mathrm{~V}$, which is clearly ascribable to the oxidation of 4-adpa molecules which were occluded between the film and the platinum substrate during the film formation. Thus, the broad peak centered at $0.63 \mathrm{~V}$ is related with the reduction of both the polymeric material and the oxidized molecules of occluded monomer.

The question that arises at this point is that of the nature of the polymeric species leading to the development of the particular voltammetric profile in Fig. 1a and b. In a further voltammetric experiment, a poly(4-adpa) film was synthesized under the same conditions as Fig. 1a. The film was allowed to dry for $24 \mathrm{~h}$ under vacuum. The electrochemical behavior of that film is shown in Fig. 2, where a new redox process develops at $0.47 / 0.34 \mathrm{~V}$. Both the shape and the potential of the first redox process in Fig. 2 fit well with that related with the Pani redox transition from its insulating leucoemeraldine to its conducting emeraldine form. If we assume that the same process is occurring for poly(4-adpa) at $0.45 \mathrm{~V}$, the slow transfor-
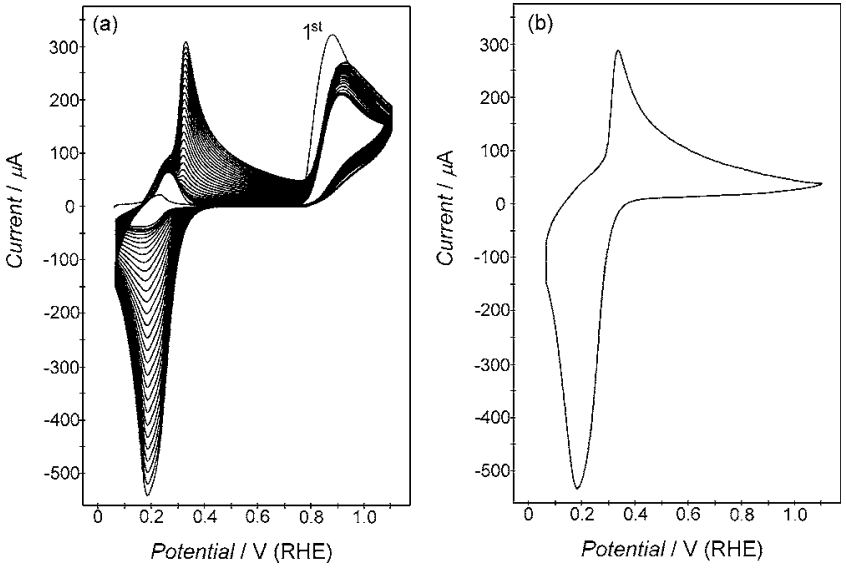

Figure 3. (a) CVs recorded during the electrochemical oxidation of $5 \mathrm{mM}$ 2-adpa in $1 \mathrm{M} \mathrm{HCl}$ on a platinum electrode. (b) Voltammetric response of poly(2-adpa) in $1 \mathrm{M} \mathrm{HCl}$ medium free of 2-adpa monomer. Scan rate $50 \mathrm{mV} \mathrm{s}^{-1}$.

mation of oligomeric chains into polymeric ones could explain the behavior observed. In this way, the electrochemical oxidation of 4-adpa molecules yields, in the first steps, short oligomeric chains whose oxidation potential is found to be around $0.65 \mathrm{~V}$. Later, these oligomers can interact chemically, forming longer chains and/or branching in such a way that the redox processes are observed at less positive potentials, virtually matching those of Pani. Under
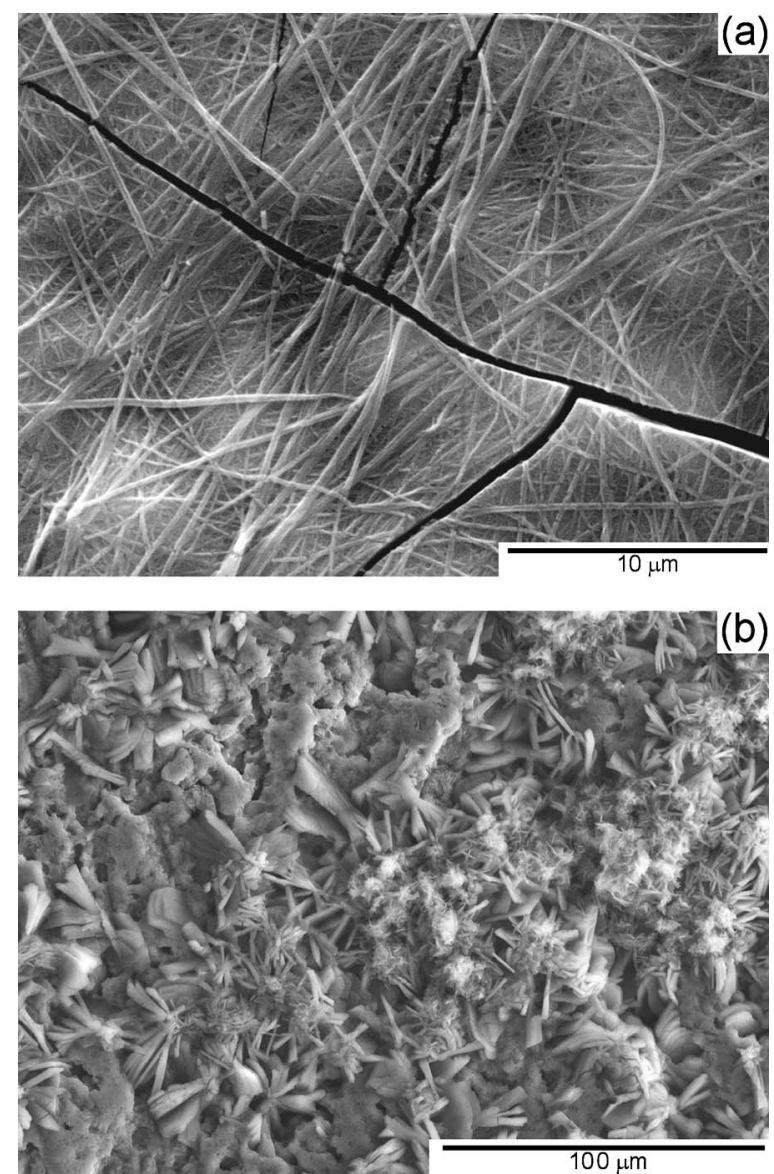

Figure 4. SEM images obtained for a graphite electrode covered with (a) poly(4-adpa) at $3000 \times$ and (b) poly $(2$-adpa) at $500 \times$. Polymers deposited after 30 potential cycles in their respective monomer solutions. 

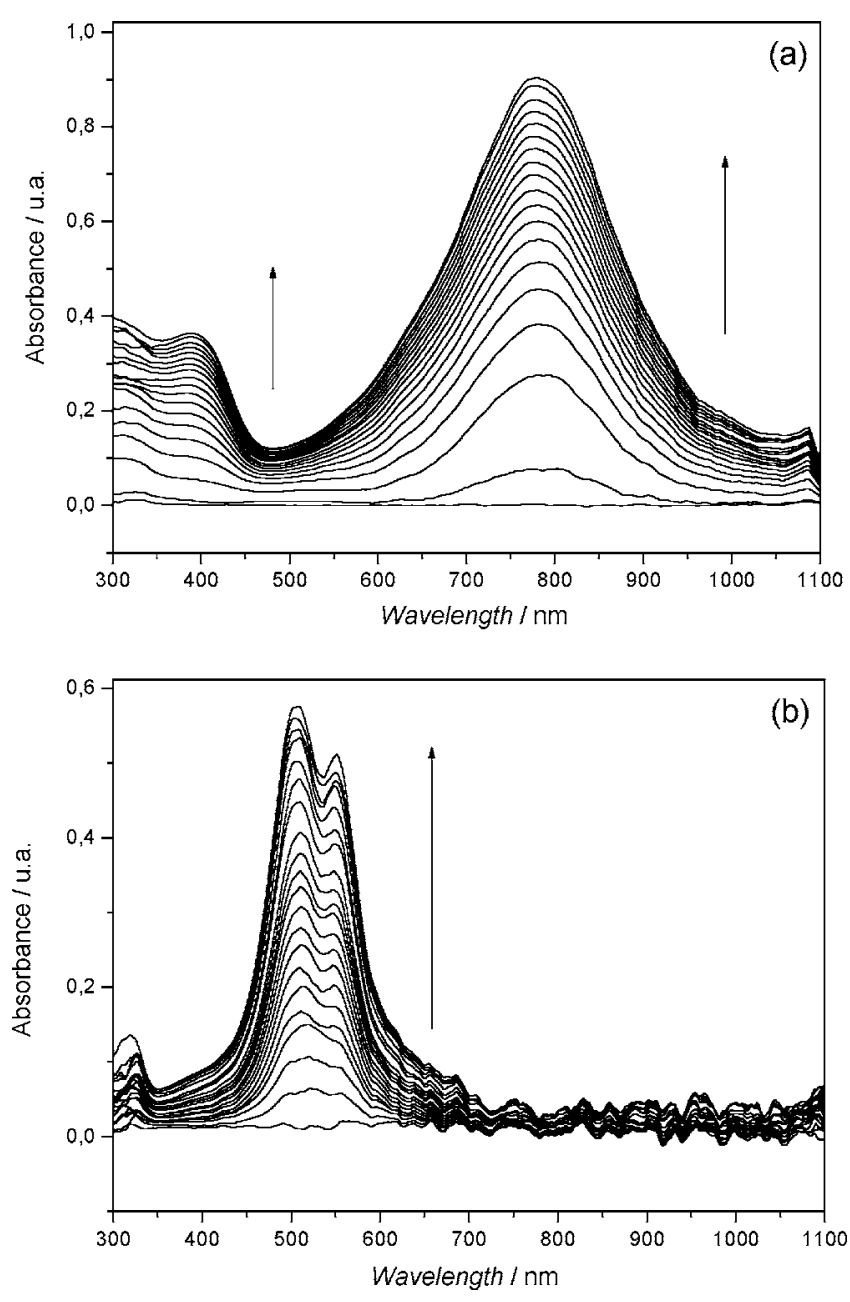

Figure 5. In situ transmission UV-visible spectra recorded in $1 \mathrm{M} \mathrm{HCl} \mathrm{me-}$ dium during the electrochemical polymerization of (a) $2.5 \mathrm{mM} 4$-adpa at $0.8 \mathrm{~V}$ and (b) $5 \mathrm{mM}$ 2-adpa at $1.1 \mathrm{~V}$. Spectra were collected every $10 \mathrm{~s}$.

those conditions, the voltammetric charge related with the redox process of the oligomeric species at $0.65 \mathrm{~V}$ should decrease due to the progressive disappearance of the oligomeric component, which seems consistent with the results obtained in the experiments.

We focus now on the electrochemical oxidation of the isomer species 2-adpa under similar experimental conditions to those employed for the para substituted monomer. Thus, Fig. 3a shows CVs recorded for a platinum electrode immersed in $1 \mathrm{M} \mathrm{HCl}$ which contained $5 \mathrm{mM}$ 2-adpa. Here, contrary to the result obtained for 4-adpa, the reversible reduction of oxidized 2-adpa molecules cannot be detected on the reverse scan, thus showing that the chemical reaction coupled to the electrochemical transfer is faster in this case. Besides, the formation of oligomeric species from the oxidized monomer is strongly suggested by the broad cathodic current developing at around $0.2 \mathrm{~V}$ on the reverse sweep. The product of this cathodic reaction can be oxidized in subsequent scans under a broad current peaked at around $0.23 \mathrm{~V}$. Finally, it can be also observed that increasing the number of potential cycles results in the development of a sharp main anodic peak at $0.32 \mathrm{~V}$. All these features point to the growth of an electroactive species on the platinum substrate, which is named poly(2-adpa).

The platinum electrode covered with poly(2-adpa) was extracted from the polymerization solution, rinsed with $1 \mathrm{M} \mathrm{HCl}$ to remove any rest of monomeric species, and then immersed in a clean background electrolyte containing $1 \mathrm{M} \mathrm{HCl}$ which was free of 2-adpa monomer. A simple visual inspection of the electrode surface con-
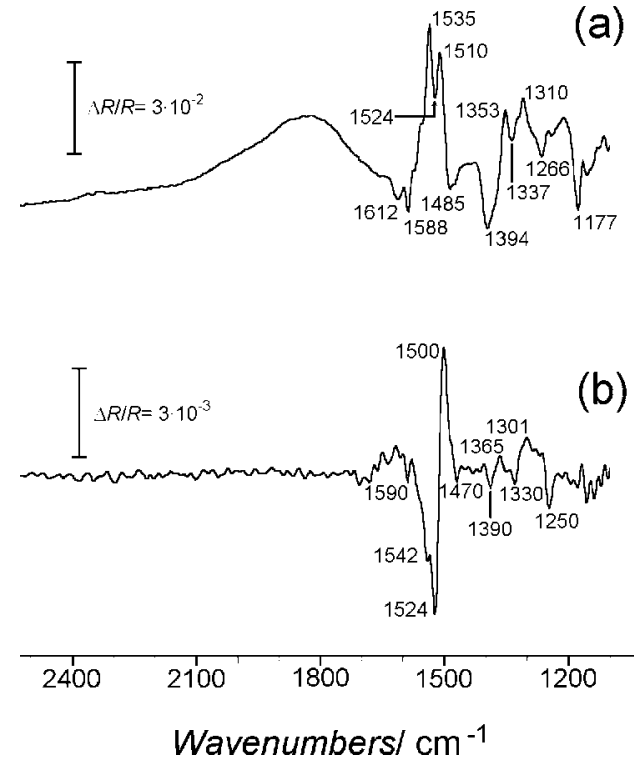

Figure 6. In situ FTIR spectra collected in $0.1 \mathrm{M} \mathrm{HCl}$ medium for (a) poly(4-adpa) and (b) poly(2-adpa) electropolymerized on Pt electrodes. Reference potential $0.1 \mathrm{~V}$. Sample potentials (a) 0.8 and (b) $0.7 \mathrm{~V} .500$ interferograms recorded at each potential. $8 \mathrm{~cm}^{-1}$ resolution.

firmed the existence of significant differences between poly(4-adpa) and poly(2-adpa) morphologies because the latter is not obtained in the form of an occluding film. Also, the colors of the synthesized materials are quite different, greenish for poly(4-adpa) and dark brown for poly(2-adpa). The electrochemical response in hydrochloric acid medium of a freshly synthesized poly(2-adpa) is displayed in Fig. 3b, for which only one redox process can be discerned at around $0.2 \mathrm{~V}$. This pair of peaks matches with the low potential redox process that develops during the electrochemical oxidation. Despite that the chemical structure of poly(2-adpa) is analyzed in more detail below, it is interesting to note at this point that the voltammetric profiles of Fig. 3 are very similar to those obtained during the electrochemical polymerization of neutral $\mathrm{red}^{26,27}$ or $o$-phenylenediamine, ${ }^{28,29}$ which have been reported to contain phenazine-like centers.

Morphological study. - The surface morphologies of poly(4adpa) and poly(2-adpa) grown on graphite surfaces can be examined in Fig. 4. The poly(4-adpa) coated electrode was stored for $24 \mathrm{~h}$ under vacuum in order to obtain a dry material. It was observed that 30 polymerization cycles were enough to cover all the surface of the graphite electrode. As deduced from the micrograph in Fig. 4a, the tensile stress induced by the drying process caused the fracture of the organic layer. In addition, it can be clearly discerned that the polymeric material consists of lengthy fibers of about $300 \mathrm{~nm}$ diameter which are intimately interlaced. This morphology resembles that obtained for Pani films synthesized from hydrochloric acid solutions, for which a "spaghetti-like" structure has been described. ${ }^{30}$ The structure obtained for poly(4-adpa) contrasts with that obtained for poly(2-adpa), which is displayed in Fig. 4b. This latter material shows what could be described as a "flaky" morphology. The flakes are disposed in a very compact arrangement, in such a way that the underlying graphite surface seems not to be exposed to the electrolytic medium. Further experiments have demonstrated that this morphology is reached after the coalescence of smaller structures that grow separately from each other on different points of the electrode surface. $^{31}$

In situ $U V$-visible spectroscopy results. - Figure 5a shows a set of in situ UV-visible spectra recorded during the electropolymerization of $2.5 \mathrm{mM} 4$-adpa on an indium tin oxide (ITO) electrode. The 

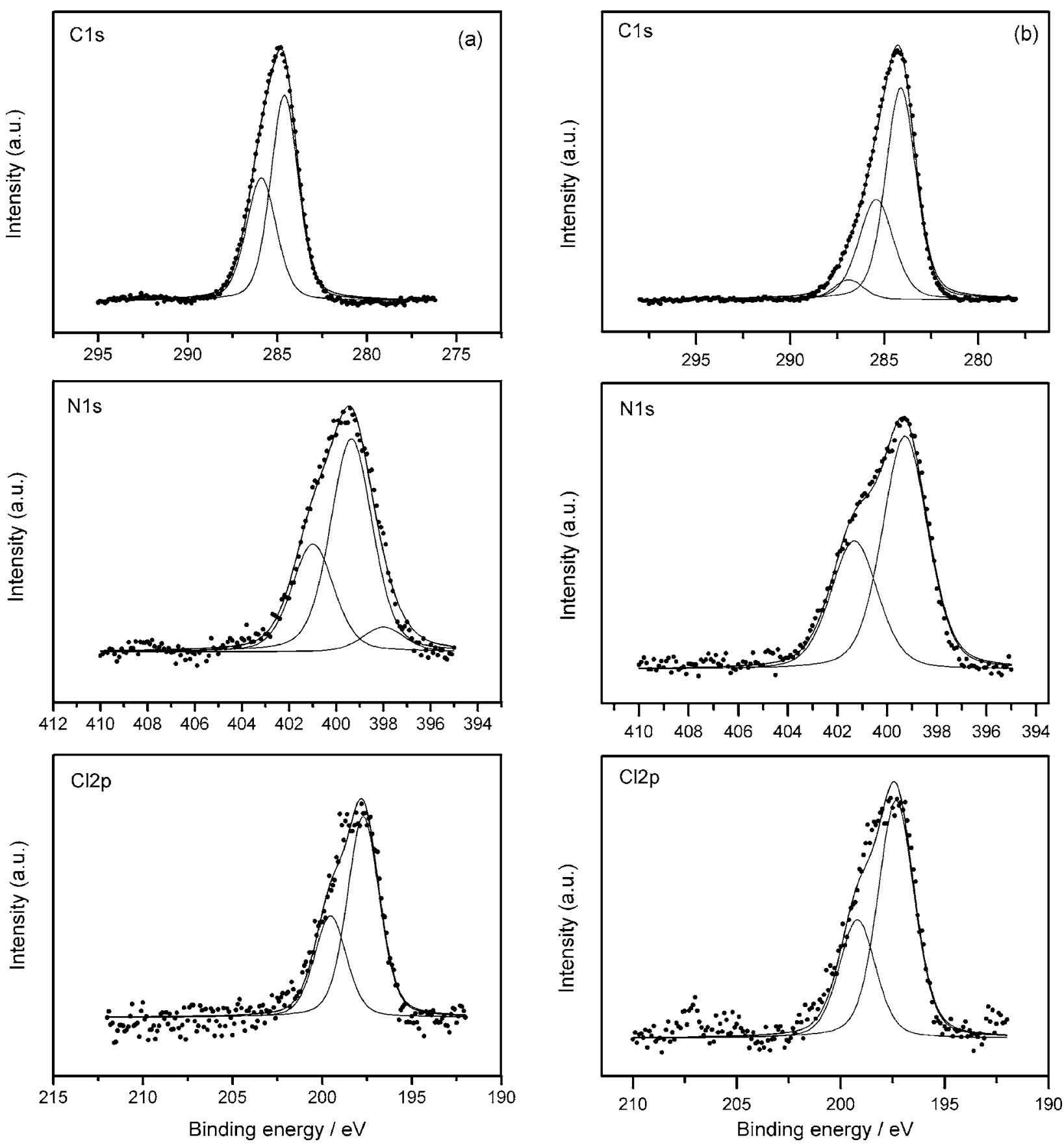

Figure 7. C 1s, N 1s, and Cl 2p high-resolution XP spectra of (a) poly(2-adpa) and (b) poly(4-adpa) films electrosynthesized on platinum substrates.

synthesis was performed at a constant potential of $0.8 \mathrm{~V}$ for $3 \mathrm{~min}$ and the spectra were collected simultaneously every $10 \mathrm{~s}$. This series of spectra reveals variations in both the intensity of the absorption and the band center position, thus pointing that the growth of poly(4-adpa) chains takes place under the experimental conditions employed. Absorption bands were assigned by comparing the spectral characteristics of Pani and some of its derivatives. Thus, the absorption centered at $315 \mathrm{~nm}(3.94 \mathrm{eV})$ could be related with either a $\pi-\pi^{*}$ or an $n-\pi^{*}$ transition. Further in situ UV-visible experiments performed in acetonitrile showed that the $315 \mathrm{~nm}$ band shifted to $336 \mathrm{~nm}$. An increase in the electronic transition wavelength as the solvent polarity increases is usually considered as a characteristic behavior of $\pi-\pi^{*}$ transitions. Moreover, the UV spectrum reported for Pani by MacDiarmid and co-workers ${ }^{32}$ displays three absorption bands matching those obtained in Fig. 5a. The $315 \mathrm{~nm}$ transition appears at slightly lower wavelengths when compared with that reported for Pani, showing that the $\pi$ conjugation extent is lower in poly(4-adpa). Partially overlapped with the $\pi-\pi^{*}$ transition band, another absorption is observed at $380 \mathrm{~nm}(3.26 \mathrm{eV})$ in Fig. 5a. This band could be assigned to a polaron- $\pi^{*}$ transition ${ }^{32}$ in the conducting form of poly(4-adpa), which is also, in this case, blue-shifted with respect to Pani and closer to the polaronic transitions observed for ring-substituted polyanilines. ${ }^{33-35}$ Zimmermann et al. reported the UV-visible spectra for the soluble species generated during the electropolymerization of 4-adpa by cyclic scanning of the potential in sulfuric acid medium. They associated a $390 \mathrm{~nm}$ absorption band with the formation of reduced tetramer structures because the polaronic states of the polymer were not detected with the ex- 
perimental setup employed. ${ }^{22}$ Accordingly, the formation of oligomers under our experimental conditions could be at the origin of the blue shift observed.

In addition to the pair of electronic transitions at the blue end of the spectra, Fig. 5a also shows a broad main absorption that peaks at around $790 \mathrm{~nm}(1.59 \mathrm{eV})$ at the initial stages of polymerization. This feature seems to undergo a slight rise in energy to $775 \mathrm{~nm}$ $(1.60 \mathrm{eV})$ for longer polymerization times. Typically, blue shifts are interpreted in terms of the reduction in the conjugation length of the absorbing species. However, it is unclear why the conjugation length should decrease at the early stages of polymerization and in a short time scale such as that employed in the present experiment. We are of the opinion that the unusually broad absorption feature appearing between 500 and $1000 \mathrm{~nm}$ could actually contain two main contributions. One of them could be the $\pi$-polaron transition in poly $(4-a d p a)^{32}$ and the other may be assigned to the bipolaron formed in a disproportionation reaction of the radical cation, which would yield a neutral molecule and a dication species, as it has been sometimes proposed for Pani. ${ }^{4,35,36}$ The assignment of the $775 \mathrm{~nm}$ band to the bipolaronic transition of poly(4-adpa) has been not considered because the potential applied to oxidize 4-adpa monomer is only $0.8 \mathrm{~V}$ and, according to the $\mathrm{CV}$ results discussed above, the pernigraniline state cannot be reached at such low potential values.

The electrochemical oxidation of 2-adpa in $1 \mathrm{M} \mathrm{HCl}$ medium at a constant potential of $1.1 \mathrm{~V}$ on an ITO substrate can be followed by means of the in situ UV-visible spectra depicted in Fig. 5b. The electronic spectra of poly(2-adpa) collected at the early stages of polymerization consist of a minor absorption at around $320 \mathrm{~nm}$ ( $3.88 \mathrm{eV}$ ) attributed to aromatic $\pi-\pi^{*}$ transitions and a single broad band centered at around $500 \mathrm{~nm}$ that, in contrast to poly(4-adpa), splits into two better-resolved peaks at $520 \mathrm{~nm}(2.39 \mathrm{eV})$ and $550 \mathrm{~nm}(2.26 \mathrm{eV})$ at longer polymerization times. Similar results were obtained by Chen et al., ${ }^{17}$ who assigned the pair of bands to the excitonic transition of benzenoid to quinoid structures. The development of two absorption peaks was explained in terms of the coexistence of two different chemical structures within the material. This hypothesis will be discussed with more detail in the light of NMR spectroscopy results. Finally, it is worth mentioning that a free carrier characteristic band which usually appears below $950 \mathrm{~nm}$ for conducting polymers cannot be detected in this case.

In situ FTIR spectroscopy results.- The in situ FTIRS technique has been applied to the characterization of the redox processes undergone by both poly(2-adpa) and poly(4-adpa). The electropolymerization of each monomer was carried out on a mirror-polished platinum disk in order to make use of an appropriate surface for the absorption-reflection technique. After polymerization, the poly(2adpa) coated electrode was carefully rinsed with $1 \mathrm{M} \mathrm{HCl}$ in order to remove any monomeric species. Then it was transferred to the spectroelectrochemical cell containing $0.1 \mathrm{M} \mathrm{HCl}$ as the supporting electrolyte. The coated electrode was maintained for $2 \mathrm{~min}$ at $0.1 \mathrm{~V}$ in order to reach the reduced state of the polymeric material. The surface of the electrode was then pressed against the $\mathrm{CaF}_{2}$ window under potential control and 100 interferograms were immediately acquired at $0.1 \mathrm{~V}$. The potential was then stepped to more positive values, $0.7 \mathrm{~V}$ for poly(2-adpa) and $0.8 \mathrm{~V}$ for poly(4-adpa), to attain the fully oxidized form of the respective polymeric material. A new set of 100 interferograms was collected at either 0.7 or $0.8 \mathrm{~V}$ and then referred to those previously acquired at $0.1 \mathrm{~V}$ to obtain the final transmittance spectrum. The procedure was repeated several times to get better signal-to-noise $(\mathrm{S} / \mathrm{N})$ ratio. Working in this way, the upward, or positive-going, absorption bands are related with vibrational modes which were active only (or mainly) at the reference potential, i.e., $0.1 \mathrm{~V}$ in this case. Downward (negative-going) features can be related with vibrational modes activated upon oxidation at the sample potential. Those vibrations that do not suffer any potential-dependent activation or deactivation are usually not present in the final spectrum for films deposited with moderate thickness.
Figure 6a shows the in situ FTIR spectrum obtained in the $1100-2500 \mathrm{~cm}^{-1}$ frequency range for poly(4-adpa). The corresponding spectrum for poly(2-adpa) is depicted in Fig. 6b. A first inspection of both spectra reveals that the intensity of the absorption bands in poly(4-adpa) are tenfold those related with poly(2-adpa). Such a discrepancy is explained by the particular experimental method followed to obtain the spectrum of poly(4-adpa), because the adherence of the deposited film to the platinum substrate was very poor. In order to assure that the poly(4-adpa) film could be retained on the surface during the handling of the electrode in the spectroelectrochemical cell, it was necessary to synthesize a relatively thick polymeric layer covering the borders of the electrode and the back side of the platinum disk as well. This experimental strategy provided the additional physical support required to keep the polymer film onto the IR-probed surface. Because poly(2-adpa) is not deposited as a spreading film, it was possible to synthesize it in the form of a thinner layer. In general, thin polymeric layers are preferred for in situ FTIRS experiments because they usually bring better resolved spectroscopic bands. Some of the vibrational modes of both polymers can be easily paired, such as those related with the formation of polaronic species upon oxidation at around 1225-1270, 1330$1340,1390-1395$, and $1470-1485 \mathrm{~cm}^{-1}$. All these features are clearly related with the appearance of diverse $\mathrm{C}-\mathrm{N}$ stretching modes coming from the oxidation of the respective secondary aromatic amines (upward absorption bands at $1300-1310 \mathrm{~cm}^{-1}$ ). Besides, the loss of aromatic rings and their conversion into quinoid structures can be easily followed in both cases from the transformation of the upward $1500 \mathrm{~cm}^{-1}$ bands into negative-going features at around $1525 \mathrm{~cm}^{-1}$. The apparent splitting of the aromatic C-C stretching that takes place at 1500 and $1535 \mathrm{~cm}^{-1}$ in the spectrum of poly(4adpa) is really an artefact due to an overlapping downward band at $1525 \mathrm{~cm}^{-1}$. The same band can be better observed in the spectrum collected for poly(2-adpa) in Fig. 6 b because its intensity is much higher in this case.

From the in situ FTIRS perspective both polymeric materials look similar. However, a careful inspection of the spectra reveals two differences between poly(2-adpa) and poly(4-adpa), such as the existence of two absorption bands at around 1612 and $1177 \mathrm{~cm}^{-1}$ in poly(4-adpa) which cannot be detected in poly(2-adpa). The negative character of the $1612 \mathrm{~cm}^{-1}$ absorption feature in poly(4-adpa) indicates that the species associated with this vibrational mode is generated at the sample potential. In addition, the frequency of $1612 \mathrm{~cm}^{-1}$ is in the spectral region of the $\mathrm{C}=\mathrm{N}$ stretching mode in species containing quinone imine structures. ${ }^{37}$ Accordingly, we ascribe this absorption band to the existence of $-\mathrm{C}=\mathrm{NH}^{+}-$moieties in poly(4-adpa). The absence of similar features in the in situ FTIR spectrum of poly(2-adpa) could imply that the amount of quinone diimines formed during the electrochemical oxidation of 2-adpa is of less significance.

With regard to the downward feature appearing at $1177 \mathrm{~cm}^{-1}$ in Fig. $6 \mathrm{a}$, an absorption at this frequency is typically present in the FTIR spectra of Pani derivatives. That mode has usually been ascribed either to the $\mathrm{C}-\mathrm{H}$ in-plane bending vibration in quinoid units, to a quinoid $\mathrm{C}-\mathrm{N}-\mathrm{C}$ vibration, or to a combination of both. ${ }^{21,38,39}$ Recently, Chen et al. ${ }^{40}$ reported that neutral red, which basically consists of a phenazine nucleus which is ring-substituted by amino and methyl moieties, shows a characteristic $\mathrm{C}-\mathrm{H}$ in plane vibration at $1180 \mathrm{~cm}^{-1}$. This mode vanished from the FTIR spectrum when neutral red was electropolymerized in strongly acidic medium to obtain the corresponding poly(neutral red). We suggest that the absence of the $\mathrm{C}-\mathrm{H}$ in plane vibration for poly(2-adpa) in Fig. $6 \mathrm{~b}$ could be related to the presence of some kind of "polymerized phenazine rings." In fact, it has already been proposed that $o$-phenylenediamine can be electrochemically polymerized, yielding phenazine rings, thanks to the presence of two amino groups in ortho position. ${ }^{41-44}$ A similar mechanism could act in the case of 2-adpa electropolymerization to give the corresponding ladder structure, as shown for the fully oxidized state in Scheme 3. An additional support to the hypothesis pointing to the formation of 
similar polymeric products from neutral red and 2-adpa can be found in the fact that the four-unit oligomer electrogenerated from $o$-phenylenediamine, which is known to contain phenazine units, shows a UV-visible spectrum quite similar to that displayed in Fig. $5 b .{ }^{44}$ This result strongly suggests the formation of analogous chemical centers in poly(2-adpa). (Scheme 3 )

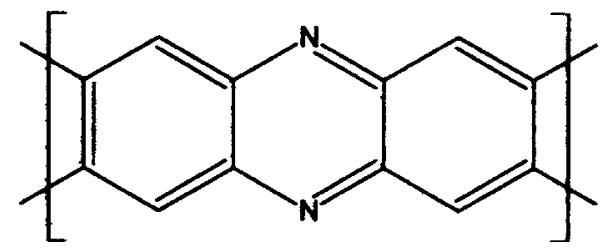

Scheme 3.

XPS film analysis. - The $\mathrm{C} 1 \mathrm{~s}, \mathrm{~N} 1 \mathrm{~s}$, and $\mathrm{C} 12 \mathrm{p}$ high-resolution spectra for electrosynthesized poly(2-adpa) are depicted in Fig. 7a. The $\mathrm{C}$ 1s peak can be fitted with a major peak at $284.6 \mathrm{eV}$ and a minor peak at $285.9 \mathrm{eV}$. The main contribution corresponds to aromatic carbon and some amount of adventitious carbon. The secondary peak can be assigned to aromatic carbons bound to amine and to imine nitrogens. ${ }^{9,43,45,46}$ The $\mathrm{C} 1 \mathrm{~s}$ binding energy (BE) of these nitrogen functionalities has been reported not to be unambiguously distinguishable from those for carbon singly bound to oxygen groups, ${ }^{45}$ but the low amount of oxygen detected in the survey spectrum (not shown) suggests that $\mathrm{C}-\mathrm{OH} / \mathrm{C}-\mathrm{O}-\mathrm{C}$ functionalities do not contribute significantly to the $285.9 \mathrm{eV}$ peak. The N1s spectrum displays a broad peak contributed by three components at 398.0 (7.1\%), $399.4(61.6 \%)$, and $401.0(31.3 \%) \mathrm{eV}$. The two lower BE peaks can be ascribed to neutral imine $(=\mathrm{N}-)$ and amine $(-\mathrm{NH}-)$ nitrogen atoms, respectively. ${ }^{9,47,48}$ The high BE peak can be assigned to positively charged nitrogen atoms, which are reported to result from protonation of quinoid imine sites. ${ }^{47,48}$ These results are compatible with both a polyaniline-like and a phenazine-like chain configuration. The $\mathrm{Cl} 2 \mathrm{p}$ line can be fitted with a spin-orbit doublet with the expected $1: 2$ intensity ratio. The $\mathrm{Cl} 2 \mathrm{p}_{3 / 2}$ component is at $197.7 \mathrm{eV}$, which corresponds to purely ionic chlorine atoms. Moreover, the $[\mathrm{Cl}] /\left[\mathrm{N}^{+}\right]$area ratio is 0.94 , thus confirming that the third $\mathrm{N}$ 1s peak is due to protonated nitrogen sites, with the positive charge fully compensated by chloride counterions. The ratio of $\mathrm{Cl}$ to the total $\mathrm{N}$ atoms results in a doping of about $30 \%$. This value is lower than that reported for Pani in its emeraldine hydrochloride form, ${ }^{47-49}$ but higher than that for copolymers of aniline and aminobenzoic acid. ${ }^{9}$

The elemental composition of poly(4-adpa) does not differ significantly from that described above. Thus, Fig. $7 b$ shows that the $\mathrm{C}$ $1 \mathrm{~s}$ spectrum presents an additional small contribution shifted by $2.8 \mathrm{eV}$ positive to the principal $\mathrm{C} 1 \mathrm{~s}$ line. This small feature could be attributed to $\mathrm{C}=\mathrm{O}$ functional groups, probably arising from a small surface oxidation upon atmospheric exposure. As far as the $\mathrm{N}$ 1s core-level region is concerned, two peaks at 399.3 (-NH-) and $401.3\left(\mathrm{~N}^{+}\right)$eV can be resolved. No imine component appeared to be necessary for a good fit of the experimental envelope. This is not, however, a significant difference with respect to poly(2-adpa), because only residual imine groups were seen in that case. Positively charged nitrogen accounts for $36 \%$ of the total $\mathrm{N} 1 \mathrm{~s}$ area. The $\mathrm{Cl} 2 \mathrm{p}$ photoelectron signal also reveals the presence of chloride species within the polymer, compensating the positive charge in nitrogen sites.

In both types of polymer film, the experimental $\mathrm{N} 1 \mathrm{~s}$ line shows a relatively well-defined shoulder at about $401 \mathrm{eV}$, instead of the well-documented tailing at high BEs for polyaniline in its emeraldine salt state. ${ }^{49}$ This result suggests that the positive charge is more localized in these polymers than in Pani and therefore, a lower conductivity should be expected. Another noticeable feature is the onset of $\pi-\pi^{*}$ shake-up satellites in the C $1 \mathrm{~s}$ and $\mathrm{N} 1 \mathrm{~s}$ spectra of poly(2adpa). These signals are characteristic of poorly conductive polymer systems with extended (not conjugated) aromatic domains. Thus, this result suggests that films formed from this isomer could be even less conducting than those obtained from 4-adpa, in close agreement with UV-visible data.

Nuclear magnetic resonance study.-In agreement with some previous studies on 4 -adpa polymerization, ${ }^{20,21}$ the voltammetric ex-

Table I. ${ }^{13} \mathrm{C}-\mathrm{NMR}$ chemical shifts recorded in $\mathrm{CDCl}_{3}$ for the three products isolated from electrosynthesized poly(2-adpa). ${ }^{\text {a }}$

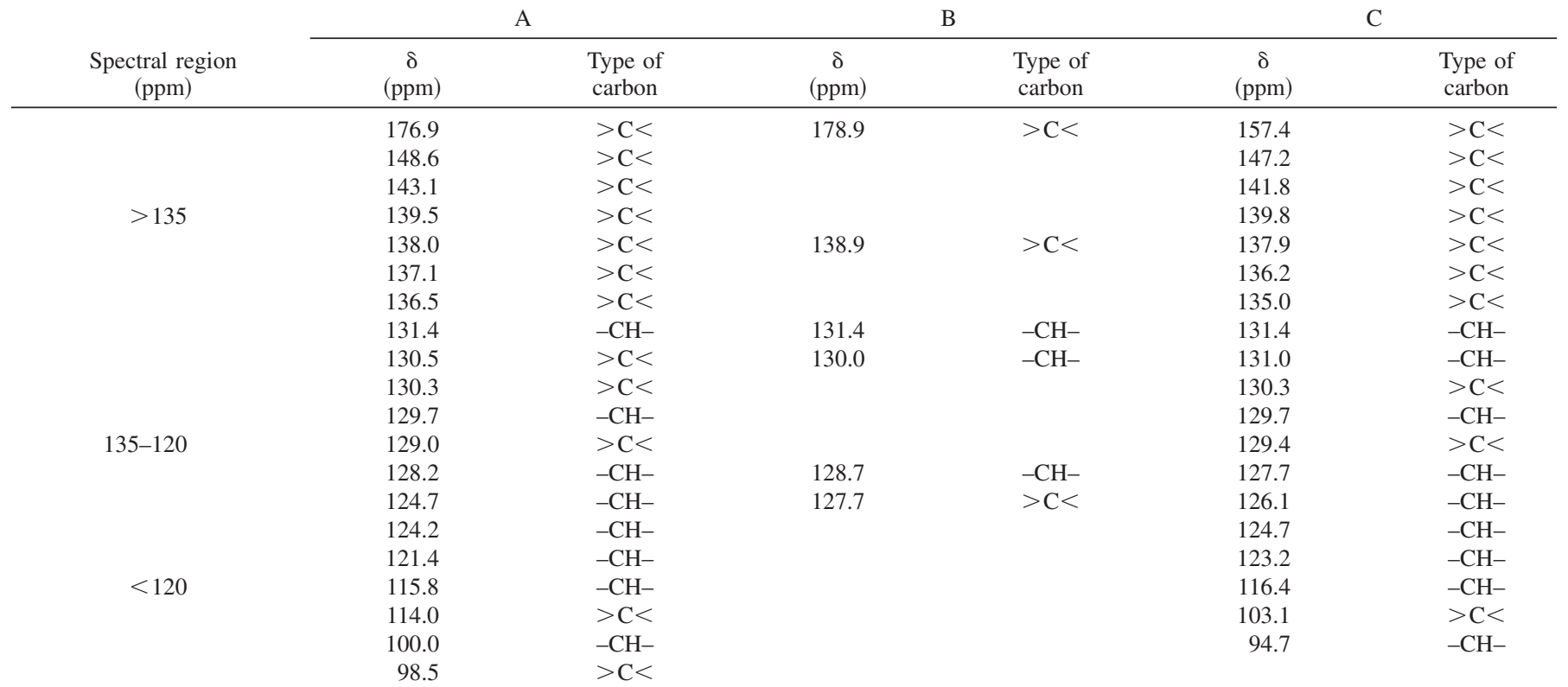

${ }^{\mathrm{a}}>\mathrm{C}<$ represents quaternary carbons and $-\mathrm{CH}-$ stands for those tertiary. 
periments reported above strongly suggest that the chemical structure of aged poly(4-adpa) is compatible with that of polyaniline. This is also supported by the fact that 4-adpa monomer contains a $\mathrm{N}-\mathrm{C}$ bond in para position to the primary amino group and, consequently, the growth of linear oligomeric chains similar to Pani is feasible. However, more precise spectroscopic information is required in order to confirm the presence of phenazine-like chemical structures in poly (2-adpa). In this way, both unidimensional $\left({ }^{1} \mathrm{H}\right.$ and ${ }^{13} \mathrm{C}$ ) nuclear magnetic resonance (NMR) experiments and bidimensional ${ }^{1} \mathrm{H}-{ }^{13} \mathrm{C}$ heteronuclear single quantum correlation (HSQC) experiments were performed to get an insight on its chemical structure.

In order to synthesize the required amount of poly(2-adpa) for the NMR study, electropolymerization of 2-adpa was performed in several experiments until about $25 \mathrm{mg}$ of a dark brown product was obtained. The basic constituents of poly(2-adpa) were separated by means of the flash chromatography technique. A mixture of eluting solvents (chloroform acetone) was used with a volume gradient varying from $4: 1$ to $1: 4$. Two components were separated under those conditions and, finally, 5\% methanol was added to the solvent mixture in order to achieve the complete separation of the third component. The solvents were evaporated and the three isolated constituents (A, B, and C) were dried under vacuum for $24 \mathrm{~h}$ at $50^{\circ} \mathrm{C}$. Compound $\mathrm{A}$ is a pale yellow solid obtained with $22 \mathrm{wt} \%$ yield. The color of compound $\mathrm{B}$ was orange and the relative amount obtained after the electrochemical synthesis is about $15 \mathrm{wt} \%$. Finally, compound $\mathrm{C}$, whose yield approached $63 \mathrm{wt} \%$, showed very intense red coloration. In a preliminary study, it was observed that all the isolated products could be well-dissolved in solvents such as acetone or chloroform, thus pointing to their oligomeric, instead of polymeric, character.

Table I summarizes the ${ }^{13} \mathrm{C}-\mathrm{NMR}$ spectroscopy signals for the isolated compounds $\mathrm{A}, \mathrm{B}$, and $\mathrm{C}$. The $\mathrm{C}-\mathrm{H}$ correlation experiments revealed the quaternary carbons from those bound to one hydrogen atom, which simplifies the assignments and helps in structure elucidation. Obviously, the presence of both primary and secondary carbons has to be fully discarded due to the chemical structure of the

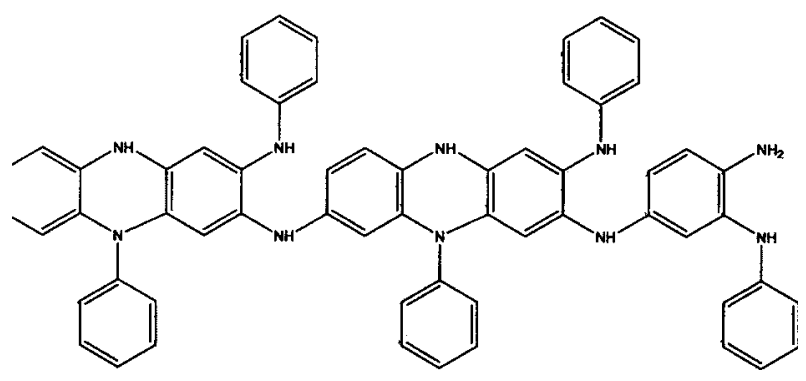

Product A

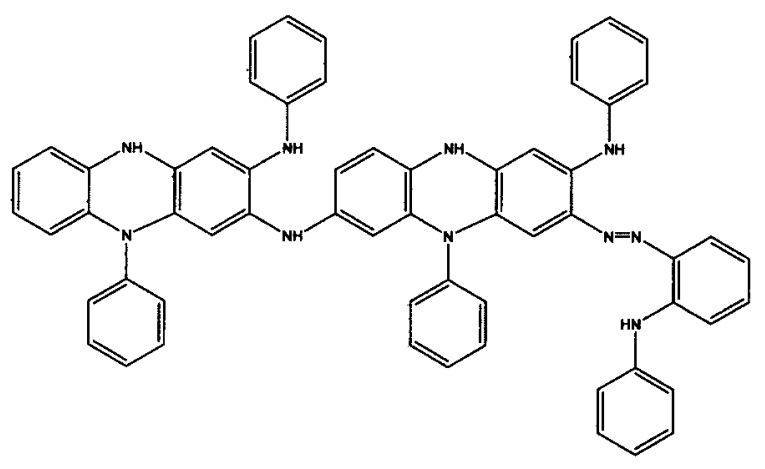

Product C monomer species. The high number of different carbons which can be detected for products A and C in Table I (almost 20 in both cases) is ascribed to the low symmetry of both substances. More precisely, for product A, 8 tertiary and 12 quaternary carbons can be distinguished, whereas product $\mathrm{C}$ contains 9 and 10, respectively. These findings virtually match the NMR results obtained by Premasiri and Euler ${ }^{50}$ for the trimer species obtained during the chemical oxidation of $o$-phenylenediamine. There, the low symmetry of the oligomer was suggested to be at the origin of the large number of NMR signals recorded. In addition, high field aromatic carbons for products $\mathrm{A}$ and $\mathrm{C}$ (those appearing below $120 \mathrm{ppm}$ ) strongly suggest the presence of a nonsymmetric phenazine unit. Accordingly, the structure of both compounds should differ slightly from that presented in Scheme 3. Tentative chemical structures which seem compatible with both the NMR data and the $\mathrm{CV}$ results for products A and $\mathrm{C}$ are proposed in Scheme 4

Product A seems formed by the addition of the 2-adpa primary amine to the $\mathrm{C} 5$ of the following monomer species to form a dimer. Additions of the same kind could repeat until up to about five monomer units are incorporated to the oligomeric chain. ${ }^{31}$ In addition to the chain growth, the presence of asymmetric phenazine units could be explained by the intramolecular attack of an amine group to the adjacent $\mathrm{C} 4$. Accordingly, the exact number of cycled phenazine units is difficult to ascertain. What seems clear is that the structure contains both open and cycled (phenazine) rings and, probably, a free $-\mathrm{NH}_{2}$ end. In relation to product $\mathrm{C}$, it is thought that its chemical structure is similar to that of product $\mathrm{A}$, thus containing both phenazine and open-ring structures. The main NMR spectroscopy difference with respect to compound $\mathrm{A}$ is the appearance of two quaternary carbon signals at 147.2 and, particularly, at $157.4 \mathrm{ppm}$, whose chemical shifts correspond to the ipso aromatic carbons (adjacent to a diazo group $\left.\mathrm{C}_{i}-\mathrm{N}=\mathrm{N}-\mathrm{C}_{i}\right) .{ }^{51}$ Chemical shifts for the other carbon signals in Table I fit well with those found for some parent structures. ${ }^{51}$ These agreements support the cap-end of the chain growth through the formation of a diazocompound by $\mathrm{N}-\mathrm{N}^{\prime}$ coupling. In addition, the fact that product $\mathrm{C}$ shows red coloration strongly suggests the presence of the diazo moiety in its structure. It is well known that aromatic diazocompounds tend to show reddish hues as a result of the more extended conjugation provided by the $-\mathrm{N}=\mathrm{N}-{ }^{52,53}$ The formation of product $\mathrm{C}$ seems the preferred route after the incorporation of a small number of monomers to the growing chain and, consequently, its relative amount increases as the polymerization time does. In this context, it is thought that product A could be better described as an intermediate species for which the $\mathrm{N}-\mathrm{N}^{\prime}$ coupling that terminates the chain growth has not yet occurred. Finally, the NMR spectroscopy results reveal that product B is highly symmetric. Only six carbon signals can be resolved in this case, half of which are related with quaternary centers. In addition, the low yield obtained for this species strongly suggests that it may be formed through a less favorable route. From these observations, it is thought that the chemical structure implies a macrocycled arrangement involving several 2-adpa units. The first and last incorporated monomer units could bind in such a way that a highsymmetry product was obtained, although the exact chemical structure has not been elucidated.

\section{Conclusions}

The electrochemical oxidation of ortho- and para-substituted aniline dimers has been performed in strongly acidic medium on different substrate electrodes. The aged poly(4-adpa) displays two different redox systems which appear centered at 0.40 and $0.65 \mathrm{~V}$, respectively. The low potential process develops at the expense of the second system and it has been attributed to the formation of longer oligomeric chains, probably nearly polymeric, whose voltammetric and morphologic characteristics in $\mathrm{HCl}$ medium resemble those of Pani. For poly(4-adpa), the occurrence of two electronic transitions involving polarons might indicate that the polaron band has little dispersion in energy and, consequently, that polarons could be isolated from each other (being a kind of localized polarons). 
However, the observation of the free-carrier absorption above $950 \mathrm{~nm}$, which also can be detected in the middle infrared region, suggests that polarons are not so localized. From this contradiction, it can be inferred that the conducting form of poly(4-adpa) could be better described as being intermediate between both localized (noninteracting) and delocalized (with high interaction) polaron models.

It has also been established that poly(2-adpa) is actually a mixture of three oligomeric products. In spite of this, the growth of poly(2-adpa) takes place mainly under a unique redox process centered at around $0.2 \mathrm{~V}$. Some infrared spectral correspondences between poly(2-adpa) and poly(4-adpa) have also been observed, in particular, those concerning some chemical entities involved in the redox processes such as the benzenoid-to-quinoid ring conversion. However, the existence of quinone-imine moieties in poly(2-adpa) equivalent to those found in the infrared spectra of both poly(4adpa) and Pani were not clearly discerned. According to the voltammetric and spectroscopic results obtained, chemical structures for the two main constituents of poly(2-adpa) have been suggested. They contain both open-ring and cycled structures resembling phenazine units.

\section{Acknowledgments}

This work has been cofinanced by the European Commission (ERDF funds) and the Spanish Ministerio de Educación y Cultura (MAT2004-01479). Un
article.

University of Alicante assisted in meeting the publication costs of this

\section{References}

1. W. S. Huang, B. D. Humphrey, and A. G. Macdiarmid, J. Chem. Soc., Faraday Trans. 1, 82, 2385 (1986)

2. J. C. Chiang and A. G. Macdiarmid, Synth. Met., 13, 193 (1986).

3. I. Mav and M. Zigon, Synth. Met., 119, 145 (2001).

4. A. Malinauskas and R. Holze, Electrochim. Acta, 43, 521 (1998).

5. Y. Wei, R. Hariharan, and S. A. Patel, Macromolecules, 23, 758 (1990).

6. A. A. Karyakin, A. K. Strakhova, and A. K. Yatsimirsky, J. Electroanal. Chem., 371, 259 (1994)

7. C. Barbero, H. J. Salavagione, D. F. Acevedo, D. E. Grumelli, F. Garay, G. A. Planes, G. M. Morales, and M. C. Miras, Electrochim. Acta, 49, 3671 (2004).

8. C. M. Li and S. L. Mu, Synth. Met., 149, 143 (2005).

9. H. S. O. Chan, S. C. Ng, W. S. Sim, K. L. Tan, and B. T. G. Tan, Macromolecules, 25, 6029 (1992)

10. R. Mazeikiene, G. Niaura, and A. Malinauskas, Synth. Met., 139, 89 (2003)

11. A. Benyoucef, F. Huerta, J. L. Vazquez, and E. Morallon, Eur. Polym. J., 41, 843 (2005).

12. F. Cases, F. Huerta, R. Lapuente, C. Quijada, E. Morallon, and J. L. Vazquez, J. Electroanal. Chem., 529, 59 (2002)

13. F. Cases, F. Huerta, P. Garces, E. Morallon, and J. L. Vazquez, J. Electroanal. Chem., 501, 186 (2001).

14. V. Rajendran, A. Gopalan, T. Vasudevan, and T. C. Wen, J. Electrochem. Soc., 147, $3014(2000)$.

15. Y. Wei, Y. Sun, G. W. Jang, and X. Tang, J. Polym. Sci., Part B: Polym. Phys., 28,
$81(1990)$.

16. W. C. Chen, T. C. Wen, and A. Gopalan, Synth Met, 130, 61 (2002).

17. W. C. Chen, T. C. Wen, and A. Gopalan, J. Electrochem. Soc., 148, E427 (2001).

18. M. A. Cotarelo, F. Huerta, C. Quijada, F. Cases, and J. L. Vazquez, Synth. Met., 148, 81 (2005)

19. M. A. Cotarelo, F. Huerta, C. Quijada, F. Cases, and J. L. Vazquez, Synth. Met., 144, 207 (2004)

20. A. Kitani, J. Yano, A. Kunai, and K. Sasaki, J. Electroanal. Chem. Interfacial Electrochem., 221, 69 (1987)

21. E. M. Genies, J. F. Penneau, M. Lapkowski, and A. Boyle, J. Electroanal. Chem. Interfacial Electrochem., 269, 63 (1989).

22. A. Zimmermann, U. Kunzelmann, and L. Dunsch, Synth. Met., 93, 17 (1998)

23. A. Petr and L. Dunsch, J. Phys. Chem., 100, 4867 (1996).

24. R. Male and R. D. Allendoerfer, J. Phys. Chem., 92, 6237 (1988).

25. H. J. Yang and A. J. Bard, J. Electroanal. Chem., 339, 423 (1992).

26. G. Inzelt and E. Csahok, Electroanalysis, 11, 744 (1999).

27. D. Benito, C. Gabrielli, J. J. Garcia-Jareno, M. Keddam, H. Perrot, and F. Vicente, Electrochim. Acta, 48, 4039 (2003).

28. J. Yano, A. Shimoyama, and K. Ogura, J. Electrochem. Soc., 139, L52 (1992)

29. M. D. Levi and E. Y. Pisarevskaya, Electrochim. Acta, 37, 635 (1992).

30. L. Duic, Z. Mandic, and F. Kovacicek, J. Polym. Sci., Part A: Polym. Chem., 32, 105 (1994).

31. M. A. Cotarelo, F. Huerta, R. Mallavia, E. Morallon, and J. L. Vazquez, Synth Met., 156, 51 (2006)

32. Y. N. Xia, J. M. Wiesinger, A. G. Macdiarmid, and A. J. Epstein, Chem. Mater, 7 , $443(1995)$

33. J. Yue, Z. H. Wang, K. R. Cromack, A. J. Epstein, and A. G. Macdiarmid, J. Am. Chem. Soc., 113, 2665 (1991).

34. M. S. Wu, T. C. Wen, and A. Gopalan, Mater. Chem. Phys., 74, 58 (2002).

35. T. C. Wen, C. Sivakumar, and A. Gopalan, Electrochim. Acta, 46, 1071 (2001).

36. G. M. Do Nascimento, V. R. L. Constantino, R. Landers, and M. L. A. Temperini, Macromolecules, 37, 9373 (2004).

37. G. Socrates, Infrared and Raman Characteristic Group Frequencies, John Wiley \& Sons, Chichester (2001)

38. J. Laska and J. Widlarz, Polymer, 46, 1485 (2005).

39. M. Hasik, A. Drelinkiewicz, E. Wenda, C. Paluszkiewicz, and S. Quillard, J. Mol. Struct., 596, 89 (2001).

40. C. X. Chen and H. P. Zhu, Bull. Electrochem., 18, 247 (2002).

41. K. Chiba, T. Ohsaka, Y. Ohnuki, and N. Oyama, J. Electroanal. Chem. Interfacial Electrochem., 219, 117 (1987).

42. X. Q. Lin and H. Q. Zhang, Electrochim. Acta, 41, 2019 (1996).

43. I. Losito, E. De Giglio, N. Cioffi, and C. Malitesta, J. Mater. Chem., 11, 1812 (2001)

44. M. A. del Valle, F. R. Diaz, M. E. Bodini, G. Alfonso, G. M. Soto, and E. D. Borrego, Polym. Int., 54, 526 (2005).

45. Y. M. Xie, T. J. Wang, O. Franklin, and P. M. A. Sherwood, Appl. Spectrosc., 46, $645(1992)$

46. L. Sabbatini, C. Malitesta, E. De Giglio, I. Losito, L. Torsi, and P. G. Zambonin, J. Electron Spectrosc. Relat. Phenom., 100, 35 (1999).

47. E. T. Kang, K. G. Neoh, and K. L. Tan, Adv. Polym. Sci., 106, 135 (1993).

48. Y. Chen, E. T. Kang, K. G. Neoh, S. L. Lim, Z. H. Ma, and K. L. Tan, Colloid Polym. Sci., 279, 73 (2001).

49. J. Yue and A. J. Epstein, Macromolecules, 24, 4441 (1991)

50. A. H. Premasiri and W. B. Euler, Macromol. Chem. Phys., 196, 3655 (1995).

51. A. Puzari and J. B. Baruah, React. Funct. Polym., 47, 147 (2001).

52. V. Kalyanar and M. V. George, J. Org. Chem., 38, 507 (1973).

53. H. Zollinger, Diazo Chemistry, Vol. 2, VCH Verlagsgesellsllschaft, Weimhein $(1995)$ 